\title{
Detection of infection with Angiostrongylus vasorum (Nematoda, Strongylida) by PCR
}

\author{
Mohammad Al-Sabi ${ }^{*}$, Pia Webster ${ }^{2}$, Jacob Willesen ${ }^{3}$, Peter Deplazes ${ }^{4}$, Alexander Mathis ${ }^{4}$, Christian Kapel ${ }^{1}$ \\ From Parasite infections of domestic animals in the Nordic countries - emerging threats and challenges. \\ The 22nd Symposium of the Nordic Committee for Veterinary Scientific Cooperation (NKVet) \\ Helsinki, Finland. 7-9 September 2008
}

\section{Background}

The French heart worm Angiostrongylus vasorum is a parasitic nematode of the pulmonary arteries and heart of canines often with severe and in some cases fatal outcome. The diagnosis is based on detection and species identification of larvae in faeces which can be problematic in Veterinary praxis especially in cases with low excreting animals. A reliable technique is thus needed for correct diagnosis and estimation of the true prevalence of infection in a population as well as for monitoring and control campaigns.

\section{Materials and methods}

A PCR was developed from the ITS2 region of the rDNA of $A$. vasorum. The sensitivity of the primers was tested with DNA from adult $A$. vasorum from a naturally infected fox and first stage larvae (L1) from an experimentally infected foxes. The specificity of the primers was tested against DNA from the most common helminth parasites of canines in Denmark and neighbouring countries. Furthermore the PCR system was applied as a confirmative test in a screening study of Danish hunting dogs and an epidemiological study of helminth parasites of wildlife in Denmark.

\section{Results}

The designed primers were very sensitive and could detect a single $A$. vasorum $\mathrm{L} 1$. The primers were also very specific and did not react with DNA from any of the common canine helminths. When used as a confirmative test, the PCR system proved to be robust and easy to work with detecting a single larva, and for use in post mortem examination of wildlife. There are practical problems that can face the PCR system such as isolating dead larvae from frozen samples and the known problem of intermittent larval excretion in dogs. These two problems can be solved by isolation of larvae by sieving instead of by Baermann sedimentation if samples were frozen, and examining consecutive fresh faecal samples.

\section{Conclusions}

We were able to design a new PCR to detect DNA of A. vasorum in canines. The test proved to be very sensitive and specific when tested in clinical and epidemiological studies. The test will be further applied in many epidemiological and clinical studies to come.

\section{Author details}

${ }^{1}$ Department of Agriculture and Ecology, University of Copenhagen, DK-1871 Frederiksberg C, Denmark. ²Department of Disease Biology, University of Copenhagen, DK-1871 Frederiksberg C, Denmark. ${ }^{3}$ Small animal hospital, University of Copenhagen, DK-1871 Frederiksberg C, Denmark. ${ }^{4}$ Institute of Parasitology, University of Zurich, CH-8057 Winterthurerstrasse 266A, Zurich, Switzerland.

Published: 13 October 2010

doi:10.1186/1751-0147-52-S1-S9

Cite this article as: Al-Sabi et al:: Detection of infection with

Angiostrongylus vasorum (Nematoda, Strongylida) by PCR. Acta

Veterinaria Scandinavica 2010 52(Suppl 1):S9. 